\title{
Los cuerpos, mercancía de las mujeres en el teatro de Patricia Suárez. Sobre Las polacas
}

\author{
The bodies, merchandise of the women in the theater of Patricia Suárez. \\ About Las polacas
}

\author{
Néstor Damián Ramos, Marcela Arpes \\ damramos05@hotmail.com,marpes@uarg.unpa.edu.ar \\ Universidad Nacional de la Patagonia Austral - Unidad Académica Río Gallegos \\ Av. Piloto "Lero" Rivera y Av. Gdor. Gregores S/N - Río Gallegos - Santa Cruz - Argentina
}

Recibido: 20/04/2020. Aceptado: 11/09/2020

\section{RESUMEN}

El presente trabajo pretende analizar la representación del cuerpo femenino como mercancía, en la trilogía teatral Las polacas de la escritora y dramaturga argentina Patricia Suárez. En las piezas que integran el libro, el cuerpo de la mujer es concebido como un bien de transacción y consumo, con valores cuantificables en dinero, el cual puede ser fácilmente reemplazado y desechado cuando su tiempo de "uso" ha caducado. Al tratarse de cuerpos destinados a la explotación sexual, estos se encuentran en una situación de sometimiento constante, reflejo de las relaciones de dominación masculina expuestas en su forma más cruda y brutal.

Para realizar dicho análisis, partiremos desde los estudios de la antropología de género, donde se da cuenta de la posición subordinada que históricamente han tenido las mujeres en la sociedad patriarcal, pasando por su explotación económica como mercancía de cambio, regida por los mecanismos de tipo capitalista.

Palabras clave: Teatro argentino; Patricia Suárez; Cuerpo femenino.

\begin{abstract}
The present paper tries to analyze the representation and objectification of the feminine body, in the theater trilogy Las polacas of the Argentine writer and dramatist Patricia Suárez. In the three pieces that make up the book, the woman's body is conceived as an object with quantifiable values in money, which can be easily replaced and discarded when its "use" time has expired. As these are bodies destined for sexual exploitation, they are constantly subjected, both socially and economically, to relations of male domination that exposed in their most crude and brutal form.

To perform this analysis, we will start from the studies of gender anthropology, where one can realizes the subordinate position that women have historically had in patriarchal society, through their economic exploitation as a commodity of change, governed by capitalist type mechanisms.
\end{abstract}

Keywords: Argentine Theater; Patricia Suárez; Female body. 


\section{INTRODUCCIÓN}

En la lógica del sistema capitalista, los sujetos son concebidos como «instrumentos» utilitarios y con funciones determinadas, los cuales perciben alguna retribución monetaria a cambio de su fuerza de trabajo. De esta manera, el sujeto deja de entenderse como tal para convertirse en un objeto funcional al sistema y cuyo valor está regido por las leyes del mercado. El capitalismo se nutre y se consolida por medio de esta relación de sometimiento de los sujetos quienes también reproducen, en el ámbito privado, las mismas relaciones de explotación.

En este sentido, la sociedad patriarcal-capitalista se ha constituido en base a las relaciones de dominación que los hombres han ejercido históricamente sobre las mujeres, las cuales han estado impedidas de decidir sobre sus vidas y sus cuerpos. Esta imposibilidad de decisión ha convertido a la mujer en un ser subalterno, entendida más como objeto «decorativo» al servicio del hombre, que como un sujeto autónomo. Esta posición subordinada a la que ha sido relegada no sólo es aprovechada por el hombre sino también por el mercado, el cual ve en su cuerpo un «bien» que tiene y debe ser explotado, convirtiéndose en un objeto supeditado a la lógica del sistema capitalista.

El presente trabajo pretende analizar la objetualización del cuerpo femenino, entendido como un bien de transacción y consumo, en la trilogía teatral Las polacas $^{l}$ de la dramaturga y escritora argentina Patricia Suárez. La importancia de estudiar esta obra particular radica, principalmente, en la delicada problemática que aborda: la explotación sexual de la mujer. Si bien las piezas que integran el libro se enmarcan en el período de la gran oleada inmigratoria de principios del siglo pasado, la cuestión del tráfico y el sometimiento sexual no dejan de ser flagelos que traspasan las barreras del tiempo y que aún perduran en la sociedad. De alguna manera, Las polacas refleja, con algunos matices y diferencias, los procedimientos utilizados por las redes de trata en la actualidad.

Para llevar a cabo la presente investigación, se ha adoptado una metodología de índole cualitativa-interpretativa, trabajando con los lineamientos propios de la investigación literaria en el ámbito de la literatura argentina, más específicamente en la dramaturgia contemporánea. En cuanto a su estructura, la primera parte del trabajo se enfoca en el impacto que ha tenido la gran corriente inmigratoria europea en la Argentina de principios del siglo XX y su relación con el surgimiento de las principales organizaciones criminales dedicadas al mercado sexual desde una perspectiva histórico-social. Para realizar dicho análisis, se han consultado una serie de artículos enfocados particularmente en el surgimiento y consolidación de dichas organizaciones, en especial la Zwi Migdal, organización criminal de origen judío que operó durante las primeras décadas del siglo XX en la Argentina. El negocio de la Migdal se basaba, fundamentalmente, en la explotación sexual de mujeres europeas, las cuales eran traídas engañadas por sus miembros y forzadas a ejercer la prostitución. La segunda parte del trabajo se centra en el análisis del objeto literario desde las perspectivas teóricas que abordan la cuestión de la corporeidad y su relación con el mercado, más precisamente en la mercantilización del cuerpo femenino.

\footnotetext{
${ }^{1}$ Existen dos ediciones de este libro. La primera, publicada en el año 2002, consta de las siguientes piezas: «Historias tártaras», «Casamentera»y «La Varsovia». En la segunda edición, publicada en 2017, se suprimió «Historias tártaras» y se agregó «Desván», siendo la pieza que cierra la trilogía. Para el presente trabajo se tomarán en cuenta ambas ediciones: Suárez P. (2006). Las polacas. Buenos Aires: Ediciones Teatro Vivo y Suárez, P. (2017). Las polacas. Rosario: Baltasara Editora.
} 


\section{MARCO DE REFERENCIAS}

\section{Marco histórico:}

En nuestro país, las organizaciones dedicadas a la prostitución tuvieron su gran auge durante las primeras décadas del siglo XX, producto de la gran corriente inmigratoria surgida a finales del siglo anterior. La incipiente industria estaba dando sus primeros pasos en el país lo que, sumado al aumento de las tierras destinadas para el cultivo, hicieron de la Argentina un lugar atractivo para los extranjeros, en especial para aquellos provenientes de Europa Oriental, quienes escapaban del hambre y la miseria, y buscaban un lugar próspero para asentarse y progresar.

A pesar de que, en un primer momento, se pensó que los inmigrantes se asentarían en las provincias del interior, las cuales estaban escasamente pobladas, la mayoría de estos se radicaron en las grandes ciudades, en especial Buenos Aires y Rosario. Esta inmigración provocó profundos cambios en la estructura social y cultural de estas ciudades, las cuales se preciaban de tener una población cultural y racialmente «homogénea». Incluso, se había llegado a un punto en que la población foránea había superado, en pocos años, a los nativos. Como consecuencia de este choque cultural, existieron grandes fricciones entre los recién llegados y los argentinos, siendo muy frecuentes los actos discriminatorios y los enfrentamientos violentos.

Con respecto a los inmigrantes que arribaron al país, la mayor eran hombres jóvenes y solteros, que superaban en gran número a las mujeres de su misma procedencia. Este desbalance poblacional provocó que el mercado sexual proliferara, debido a la creciente demanda de mujeres para satisfacer las "urgencias" de estos jóvenes hombres. La falta de mujeres, sumado al despertar económico de la metrópolis, "impulsó la codicia de algunos hombres que vieron como gran negocio traer a estas costas a jóvenes mujeres europeas con el pretexto de ofrecerlas en matrimonio" (Scarsi 2011: 1). La miseria y pobreza que azotaba a Europa Oriental durante ese período propició una gran oportunidad para la consolidación de organizaciones criminales, las cuales aprovecharon la vulnerabilidad y la desesperación de muchas mujeres y sus familias.

Estas organizaciones vieron en el mercado sexual un negocio increíblemente rentable. Inclusive, la prostitución era, de alguna manera, socialmente aceptada e incluso los proxenetas contaban "con la complicidad, la tolerancia o hasta la asociación con agentes del Estado, ya sea la policía, los agentes migratorios, las fuerzas de seguridad, jueces, políticos o personajes prominentes de la actividad económica, social y en algún caso religiosa" (Schnabel, 2010: 3). Asimismo, durante esta etapa se fueron consolidando las principales organizaciones criminales de origen europeo, como la MILIEU francesa; o la Sociedad Israelita de Socorros Mutuos Varsovia, posteriormente conocida como Zwi Migdal, la más famosa y de mayor alcance de las dos.

Si bien ambas organizaciones se enfocaban en el mismo negocio, es decir en la «trata de blancas» ${ }^{2}$, existían ciertas diferencias entre ambas. Mientras que el vínculo establecido entre el macró de la MILIEU con la mujer engañada se basaba en un lazo puramente afectivo, el cual podía concluir en cualquier momento; el de la Zwi Migdal se «unía» a su víctima por

\footnotetext{
${ }^{2}$ La «trata de blancas» se vincula, por oposición, a la «trata de negros», es decir a la compra y explotación de esclavos africanos. Esta denominación demuestra las similitudes que comparten ambos «negocios», sólo que en este caso se trataba de mujeres blancas y europeas.
} 
medio del matrimonio. Aunque los casamientos concertados entre el caftén ${ }^{3}$ de la Migdal y la futura esposa eran totalmente falsos, al estar enmarcados en el ámbito religioso resultaban uniones mucho más difíciles de romper debido a las profundas creencias de estas mujeres. Elisa Cohen de Chervonagura sostiene que en eso radica "la perversidad del vínculo creado por la Migdal porque al incorporar elementos rituales judíos y corromper con la riqueza, acostumbraba a las mujeres a vivir con mucho dinero lo cual las llevaba a no querer salir de la organización" (2011: 37). En este sentido, el éxito de la Zwi Migdal se debió precisamente al fuerte vínculo de dependencia económica que existía entre la mujer engañada con el caftén.

Respecto a las víctimas que captaban los miembros de la Zwi Migdal, éstos se centraban en jóvenes mujeres campesinas, la mayoría de origen judío, a las cuales engañaban con promesas de matrimonio y prosperidad en la Argentina. Para Raúl A. Schnabel, la captación de mujeres judías para la explotación sexual se debió a tres causas principales: "la extrema pobreza de los judíos y del resto de la población en Europa, las rígidas leyes religiosas y la posibilidad de una mejor vida en otros países" (2010: 7). En cuanto al método utilizado, este consistía en que el caftén se presentaba a la familia de la futura «esposa» como un hombre adinerado y exitoso, el cual estaba en busca de una mujer para casarse. Los padres, desesperados por el hambre y la miseria que padecían, entregaban a sus hijas a cambio de una dote que concertaban con el pretendiente. En algunas ocasiones, el caftén arreglaba con una casamentera, la cual se encargaba de buscarle mujeres jóvenes y acordaba la unión con los padres de estas.

Luego de llegar a un acuerdo y concertar la «compra», tanto el caftén como su futura «esposa», se embarcaban hacia la Argentina, en donde eran inmediatamente llevadas a los prostíbulos y obligadas a ejercer el oficio. Si bien existieron innumerables denuncias penales respecto del trato de las mujeres extranjeras y de origen judío, sus problemáticas no eran atendidas o priorizadas por las autoridades, quienes al estar "infectadas de antisemitismo, racismo y discriminación, no prestaban mayor atención a dichos acontecimientos" (Scarsi, 2011: 15). Este desentendimiento conllevó a que las redes de trata proliferaran en las principales ciudades del país y se volvieran cada vez más poderosas y lucrativas, a costa de la explotación de las mujeres y su cuerpo.

\section{Marco teórico:}

El presente trabajo se ha abordado, primeramente, desde la perspectiva teórica planteada por Silvia Federici en su libro Calibán y la bruja. Mujeres, cuerpo y acumulación primitiva. En el mismo, Federici sostiene que la explotación de las mujeres constituyó un factor central en el proceso de acumulación capitalista, "en la medida en que las mujeres han sido las productoras y reproductoras de la mercancía capitalista más esencial: la fuerza de trabajo" (2004: 16). Afirma que las relaciones de dominación sobre las mujeres se basan, fundamentalmente, en el no reconocimiento de la producción y reproducción de la fuerza de trabajo como una actividad remunerada. Esto mismo ha determinado que la mujer y su cuerpo sean concebidos como un recurso o servicio, cuya única función se restringe a la producción y a la crianza de los futuros trabajadores.

Asimismo, este sistema de sometimiento contribuyó a la consolidación del orden patriarcal, el cual se basa "en la exclusión de las mujeres del trabajo asalariado y su subordinación a los

\footnotetext{
${ }^{3}$ El término «caftén» es un término del lunfardo y era utilizado para designar a los rufianes judíos debido a "las largas capas que usaban los judíos ortodoxos" (Schnabel, 2010: 15).
} 
hombres" (2004: 23). Mientras los hombres han logrado cierta libertad y autonomía debido a su condición de trabajadores asalariados, las mujeres han sido reducidas a condiciones de explotación casi similares a la esclavitud. De esta manera se consolidaron las relaciones de dominación masculina, en donde las mujeres se volvieron «sirvientas» a disposición del hombre. El orden patriarcal trasformó al cuerpo femenino en una «máquina» puesta al servicio del sistema capitalista. En este sentido, la institución familiar se convirtió en el espacio perfecto para perpetuar este sistema de sometimiento sobre la mujer y su cuerpo como productora y reproductora de fuerza de trabajo. Además, el hecho de restringirlas al hogar y a las tareas domésticas tuvo como finalidad alejarlas de los ámbitos laborales como trabajadoras asalariadas. Este sistema restrictivo patriarcal-capitalista fue el que convirtió a los cuerpos de las mujeres en una mercancía de consumo.

Por su parte, M. T. Alejandre Peña en "El papel de la mujer en la sociedad capitalista y los derechos humanos", sostiene que, tanto el hombre como la mujer, se han convertido en «mercancías» del sistema de producción capitalista. Al vender su fuerza de trabajo a cambio de un salario, estos se convierten en objetos funcionales al sistema que los explota. Sin embargo, la incorporación de la mujer a los espacios laborales remunerados es relativamente reciente. Durante mucho tiempo, esta fue reducida al ámbito privado, encargada del cuidado y la crianza de los hijos, sin ningún tipo de compensación económica por su trabajo. Esta condición natural como procreadora es lo que ha "condicionado su existencia, la ha sometido a una dependencia del hombre que se basa en la facultad de la mujer de ser madre, de acuerdo a razones sociales o culturales" (2000: 73). De esta manera, la maternidad es entendida como una forma de sometimiento que ha reducido y limitado a la mujer, volviéndola económicamente dependiente del hombre, quien se erige como autoridad al ser quien aporta los mayores recursos.

Para enriquecer el análisis, también se han incorporado los aportes teóricos de Georgina Sotelo Ríos y Mirtha Patricia Domínguez Chenge, en su artículo "Cosificación femenina en la era del capitalismo tardío", quienes centraron su trabajo en el proceso de cosificación femenina y cómo este se ha ido acentuado a lo largo de los años. Si bien las autoras se enfocan específicamente en la cosificación de la mujer y su relación con los medios de comunicación, resulta interesante destacar las reflexiones teóricas y el análisis que hacen sobre las relaciones de dominación masculina y la situación subordinada de la mujer en la sociedad. Históricamente, la mujer ha asumido un rol secundario, entendida más como acompañante del hombre que como sujeto autónomo capaz de tomar las riendas de sus propias acciones. Cuanto más, la mujer "se ha constituido en objeto: decorativo, sexual, de compañía, por decisión propia se ha creado una falsa autoimagen" (2014: 43). Como consecuencia de esta auto-percepción de la mujer como objeto ornamental del hombre, se consolidó la idea de valorarse por medio de sus atributos físicos. De esta manera, la mujer comienza a definirse a partir de su cuerpo y sus cualidades, lo que contribuye a su proceso de cosificación.

Por otra parte, Rosa Cobo Bedia, en su artículo "El cuerpo de las mujeres y la sobrecarga de la sexualidad", indaga los orígenes de la sexualización del cuerpo femenino y su mercantilización. Desde esta perspectiva, el proceso de sexualización, impuesto por la sociedad heteropatriarcal, es lo que despojó a la mujer de su condición de sujeto, convirtiéndola en simple objeto del deseo masculino. En este sentido, las sociedades patriarcales han establecido dos modelos exclusivos de regulación de la sexualidad de la mujer: como madre y esposa, dentro de la institución familiar, o como prostituta a disposición pública del varón. De esta manera, "las mujeres reciben el mandato de que sus cuerpos deben crearse en función de la mirada masculina y, precisamente por ello, la sexualidad debe ocupar 
un lugar central en las representaciones de lo femenino" (2015: 14). En este sentido, ambos modelos normativos se enfocan en la erotización del cuerpo femenino, lo que alimenta la idea de que las mujeres deben ser valoradas fundamentalmente por su atractivo sexual. El objetivo de este proceso es disciplinar los cuerpos de las mujeres, tanto para la producción y reproducción de la fuerza de trabajo, como así también para la disponibilidad sexual de los hombres.

Para la contextualización histórica de la presente investigación, se han consultado diversos trabajos que estudian la situación inmigratoria en la Argentina de principios del siglo XX y su relación con el auge del mercado sexual. Entre los artículos consultados se encuentran "Historia de la trata de personas en Argentina como persistencia de la esclavitud" de Raúl A. Schnabel, quien realiza un paneo histórico sobre el origen de la prostitución en nuestro país y el surgimiento de las principales organizaciones criminales enfocadas en la "trata de blancas". Al igual que Schnabel, José Luis Scarsi en "Historia de la prostitución y de la trata de personas en Buenos Aires" también se centra en este aspecto, circunscribiendo su análisis a las organizaciones que operaron en distintas zonas de la Capital Federal. Además de exponer la metodología utilizada por los integrantes para captar a sus víctimas, también incorpora fragmentos de informes policiales sobre los principales cabecillas de estas bandas. También, se pueden leer citas de algunos informes médicos hechos a las prostitutas, lo que permite conocer de primera mano las pésimas y deplorables condiciones de salud en que se encontraban. Asimismo, resulta importante destacar el artículo de Elisa Cohen de Chervonagura "La prostitución judía y su discurso a la luz de un expediente judicial", quien enfoca su análisis en el origen de la Zwi Migdal, la organización de criminal judía más importante que operó en la Argentina. En el mismo, no sólo da cuenta del contexto históricosocial en la que surgió, sino también de la metodología utilizada por sus integrantes. Resulta importante destacar este artículo debido a que la obra analizada en el presente trabajo se centra precisamente en la forma en que los miembros de la Zwi Migdal captaban a las mujeres y comerciaban con sus cuerpos.

\section{Etapa del deseo: Control y proyección sobre la mujer y su cuerpo}

La institución matrimonial se ha constituido, a lo largo de los años, como el mayor espacio de sometimiento femenino por antonomasia. Durante siglos, el matrimonio fue "visto como la verdadera carrera para una mujer; hasta tal punto se daba por sentado la incapacidad de las mujeres para mantenerse" (Federici 2004: 143). De esta forma, el matrimonio se convirtió en la única vía de subsistencia económica socialmente avalada. Por este motivo, el ejercicio de cualquier otra actividad que permitiera a las mujeres no casadas ser económicamente autónomas era reprobado de manera categórica. Estas restricciones provocaron que "las alternativas vitales para las mujeres no salgan de los límites asignados en el contrato sexual: matrimonio y prostitución" (Cobo Bedia, 2015: 9), imposiciones del sistema a favor del patriarcado.

Donde se puede observar de manera eficaz el proceso de sometimiento de la mujer es en los matrimonios arreglados, práctica muy usual y extendida en distintas culturas. En este tipo de uniones, la mujer es concebida como una mercancía de cambio, sujeta a los designios de quien posee su tutela, generalmente el padre, quien la «vende» a un pretendiente interesado a cambio de una dote. Para determinar su valor, la condición física de la mujer se constituye como un factor fundamental que determina su precio. Es decir que mientras más atributos y 
belleza, mayor será su importe de venta. Asimismo, durante el proceso de transacción, la mujer se encuentra totalmente excluida del mismo, debiendo acatar la orden impuesta sin ningún tipo de objeción. Como sostienen Sotelo Ríos y Domínguez Chenge, al no tener "capacidad de decisión sobre su cuerpo, sus deseos, sus intereses y su vida misma, la mujer ha sido un sujeto moldeable a la voluntad de ser de su otredad" (2014: 43). De esta manera se produce el proceso de mercantilización de la mujer y su cuerpo, la cual deja de ser entendida como un sujeto autónomo para convertirse en un objeto a disposición del hombre.

En Las polacas, el proceso de mercantilización del cuerpo femenino por medio del arreglo matrimonial constituye la primera etapa de un largo trayecto que culmina con su explotación sexual. En «Historias tártaras», pieza que abre la trilogía, se esboza el primer eslabón de la cadena, en donde el pretendiente-comprador va en busca de su esposa-mercancía:

\begin{abstract}
"Schlomo: Ahora mismo estoy viajando para mi pueblo; me llegó la hora de tener mujer y mis parientes me han conseguido una que es una flor... se llama Hanna... ¿era Hanna el nombre o Yana?...” (pp. 12).
\end{abstract}

Al tratarse de una transacción comercial, lo afectivo se encuentra completamente elidido en este tipo de uniones, por lo que no resulta extraño que los contrayentes ni siquiera se conozcan o hayan establecido algún vínculo previo. De alguna manera, el desconocimiento del nombre no sólo es indicio del distanciamiento emocional de Schlomo con respecto a su futura esposa, sino que también indica una cierta cosificación. Al definirla como una «flor», epíteto típico utilizado para definir a la mujer, no hace más que reforzar la noción de mujerobjeto. De hecho, Schlomo apela constantemente a esta imagen a lo largo de la pieza:

\begin{abstract}
"Schlomo: Quizá hasta pueda encontrar realmente a mi florcita... Me han dicho que es de pelo rojo y ojos gris oscuro, muy polacos; dicen que es alta y esbelta, que no tiene más de diecisiete años acabados de cumplir... -sería una mina de oro para quien hiciera de esta muchachita otra cosa que una esposa" (pp. 19).
\end{abstract}

Al describir las características físicas de su futura esposa, Schlomo proyecta e idealiza su imagen basándose en ciertos parámetros de belleza (el cabello, los ojos, la delgadez, la altura, la juventud). Debido a que se la concibe como mercancía de cambio cuyo valor está determinado por sus cualidades y atributos, no resulta extraño que este destaque y exhiba su belleza, tal como si se tratara de un trofeo. Asimismo, las palabras de Schlomo dejan entrever su pensamiento netamente utilitario, quien ve en la mujer y su cuerpo una «mina de oro» la cual puede explotar. Con el trascurrir de la pieza, Schlomo irá haciendo cada vez más explícito este aspecto, dejando entrever sus verdaderas intenciones.

En cuanto a la noción que posee con respecto a la mujer y su rol dentro del matrimonio, Schlomo responde al pensamiento normativo hetero-patriarcal de la mujer como esposa y madre. Históricamente, la división sexual ha fijado las funciones y obligaciones que hombres y mujeres deben cumplir dentro del matrimonio. De acuerdo a esta idea, cada sujeto tiene reservadas funciones específicas, las cuales están determinadas por el género. Mientras el hombre se instituido como proveedor de recursos a través del ejercicio de actividades productivas fuera del hogar, la mujer ha sido relegada al cuidado del esposo y la crianza de los hijos. En este sentido, está "determinada por la satisfacción del otro, es decir, siempre la prioridad se establecerá en función del servicio que se presta a quien así lo requiera. Es una noción subordinada al otro" (Sotelo Ríos y Domínguez Chenge 2014: 44). En la pieza, Schlomo remarca constantemente las funciones que debe cumplir una mujer dentro del matrimonio, restringiéndola exclusivamente al cuidado del esposo y la crianza de los hijos:

"Schlomo: Voy a hacer de ella la mujer más feliz del mundo; no se va a ocupar más que de su esposo y sus hijos..." (pp. 13). 
De alguna manera, esta concepción de la mujer como esposa y madre no sólo constituye una proyección idealizada, sino que también esconde una forma de sometimiento. En este sentido, la maternidad también termina siendo otra forma de subyugación. Como afirma Alejandre Peña, citando a Evelyn Reed, "las condiciones naturales de maternidad de la mujer se transformaron en las cadenas de explotación que aún se conservan" (2000: 73). La maternidad se convierte en otra forma de imposición que somete a la mujer y transforma su cuerpo en un "recurso" el cual es aprovechado y explotado no sólo por el esposo sino también por el sistema de producción capitalista. Tal como sostiene Silvia Federici, "el cuerpo femenino fue transformado en instrumento para la reproducción del trabajo y la expansión de la fuerza de trabajo, tratado como una máquina natural de crianza" (2004: 139). De esta manera, el matrimonio y la familia se fundan como instituciones esenciales de control sobre la mujer y su cuerpo.

\section{Etapa de transacción: comercialización del cuerpo femenino}

Como se ha visto anteriormente, los arreglos matrimoniales se han constituido como una de las instancias de mercantilización del cuerpo femenino más culturalmente arraigadas. En este tipo de transacciones, las condiciones de la mujer cobran una vital importancia, tanto para el «vendedor», quien establece su valor según sus habilidades y sus cualidades físicas; como para el «comprador», quien paga un determinado monto dependiendo de su valía. En «Casamentera» se plantea claramente este proceso de tasación y compra del cuerpo femenino. La pieza gira en torno a la negociación entre las dos partes interesadas: por un lado está Schlomo, el pretendiente que busca «comprar» una esposa; y por otro se encuentra Golde, la casamentera, quien funciona como intermediaria de la familia de la novia e intenta venderla según las complacencias del cliente:

\footnotetext{
"Golde: Bonita, por sobre todo bonita. (Schlomo asiente). Rubia. (Schlomo asiente). De cabello largo, muy largo, que le cubra las espaldas. ¿Así es como la quiere?
}

\section{Schlomo: Sí.}

Golde: Y joven, casadera.

Schlomo: Sí.” (pp. 53-54).

Al tratar su cuerpo como una mercancía negociable y con un determinado precio, la mujer deja de percibirse en su subjetividad, lo cual "conduce a un sentido de disociación con respecto al cuerpo, que viene redefinido y reducido a un objeto con el cual la persona deja de estar inmediatamente identificada" (Federici 2004: 183). Esta disociación con respecto al cuerpo provoca que su mercantilización, de alguna forma, se normalice. La escena donde Schlomo y Golde discuten sobre las cualidades físicas de Emma constituye un ejemplo claro de este proceso de disociación, en donde el valor de la mujer es definido exclusivamente por su cuerpo:

"Schlomo: Emma tiene la nariz torcida.

Golde: ¿Torcida? No lo había notado.

Schlomo: Y es chueca. Se levantó la falda...

Golde: (interrumpiéndolo): ¿Se levantó la falda? 
Schlomo: Para enseñarme una cicatriz en la rodilla... y... ¡tiene las piernas muy flacas. $[\ldots]$

Schlomo: ¡No tiene carne en las piernas! ¡Y la frente! ¡Tan alta! Vista de lejos, parece una mujer calva. [...]

Schlomo: ¿Y las pecas? Usted sabe que las pecas en una mujer no gustan. [...]

Schlomo: (...) ¿Cómo podría valer más Emma que su hermana, señora Golde?” (pp. 73-74)

Al enumerar los «defectos» físicos de Emma, Schlomo pretende disminuir su valor con respecto a su hermana Edit y, por consiguiente, bajar su precio de venta. Como se puede apreciar, los patrones que maneja Schlomo con respecto a la valía de una mujer responden a ciertos cánones de belleza impuestos por la sociedad patriarcal. En este sentido, la mujer es tasada exclusivamente según su atractivo sexual, el cual está "muy por encima de esas otras características que se han dejado de lado en un catálogo que no incluye más que mínimos ingredientes de la inteligencia" (Federici 2014: 44). Por otra parte, Golde considera que la simpatía y la gracia en una mujer son cualidades incluso más valiosas que la belleza misma. No resulta casual que la casamentera apele a este recurso, ya que Emma no cumple con los parámetros que maneja Schlomo, por lo que Golde debe destacar otras cualidades para poder vender la «mercancía» a un buen precio. Esta recalca la locuacidad de Emma para entretener a los clientes con su buena plática, lo que considera fundamental para que el negocio sea más rentable y genere mayores ganancias:

“Golde: Va a tener que pagar más por Emma. Le dará su buena ganancia, ya verá. Además, ha visto: sabe dar conversación entretenida. Eso significa para su negocio muchos rublos más. Le entretendrá a los clientes” (pp. 75).

Al igual que Schlomo, Golde concibe a la mujer desde una visión mercantilista, lo cual se refleja en los términos que utiliza, tales como «ganancia», «negocio», «clientes». Sin embargo, los parámetros que toma para determinar el valor de la «mercancía» son distintos a los de Schlomo. Para Golde, la valía de una mujer radica en su intelecto y en su utilidad para las labores prácticas, mientras que para Schlomo el atractivo físico prima por sobre cualquier otro valor. Este proceso de mercantilización extremo del cuerpo femenino llega a su máxima expresión cuando comienzan a regatear el precio de Emma, en donde cada una de las partes intenta llegar a un acuerdo que les sea conveniente a ambos:

"Schlomo: ¿Cuánto más por Emma?

Golde: El doble.

Schlomo: ¡Usted está loca!

Golde: El doble. Y unos ciento cincuenta rublos para el médico de Moishe. [...]

Schlomo: Mil quinientos más.

Golde: Dos mil quinientos.

Schlomo: Mil ochocientos.

Golde: Dos mil. Y los gastos del niño.

Schlomo: Dos mil.

Golde: Está bien” (pp. 78). 
Finalmente, las partes logran concretar un precio por Emma y su cuerpo, concluyendo el proceso de transacción. La frialdad de la disputa, en donde cada uno baraja distintos precios, no hace más que agravar la condición de «mercancía» en un grado extremo. El hecho que la opinión de Emma no es tomada en cuenta en este asunto, es otro indicio que da cuenta de su condición subordinada a la voluntad de terceros.

\section{Etapa del desecho y el reemplazo: el cuerpo "nuevo" y el ocaso del "viejo"}

Bajo el sistema de explotación sexual, el cuerpo de la mujer es tratado como cualquier otro bien de consumo, el cual puede ser fácilmente desechado y reemplazado por uno «nuevo» y en mejores condiciones cuando este deja de ser económicamente rentable. Al no poder cumplir con su labor de manera satisfactoria, ya sea por la edad o por el padecimiento de alguna enfermedad, se produce el proceso de sustitución y posterior descarte del cuerpo. En el negocio de la prostitución, la condición física constituye un factor fundamental para la rentabilidad del mismo. Mientras más joven, bella y saludable sea la mujer mayor será la demanda de los clientes, lo que conllevará mayores ganancias. En contraposición, las mujeres que ya no cuentan con estos atributos se convierten en un escollo para los proxenetas, quienes no pueden ganar dinero, por lo que deciden deshacerse de ellas.

En «La Varsovia»se plantea la dicotomía entre la «nueva mercancía», encarnada por Hanna, más joven y vital, y la «vieja mercancía», representada por Mignón. Como se tratan de cuerpos destinados al ejercicio de la prostitución, estos tienen un determinado tiempo de «vida útil». En esta pieza en particular, existe una marcada contraposición entre el «viejo» producto y el «nuevo» que llega para reemplazarlo. Los motivos que se expresan en esta disputa son principalmente la vejez y la consecuente pérdida del atractivo físico. Estas condiciones resultan desfavorables para la rentabilidad del negocio y, por lo tanto, debe ser descartada. La discusión entre Mignón y Hanna versa precisamente sobre esta cuestión:

"Hanna: Usted va a cumplir treinta y seis años, el próximo agosto, Ester, Schlomo me lo dijo: usted ya no le sirve.

Mignón: ¡Ja! ¿Así le dijo? ¿Cómo le dijo en realidad? «Mi hermana está ya grande para estar todo el día en la peletería y necesita de su ayuda, querida Hanna». Es un truco.

Hanna: Schlomo me dijo: «los clientes la desprecian, porque su carne es macilenta y flácida y está muy entrada en carnes». (Pausa. Desconcierto de Mignón). «Después de la medianoche ya está agotada. Amarilla y enclenque, huele mal».

Mignón: Usted está mintiendo.

Hanna: «Tiene el grano malo. En cuanto los clientes lo sepan dejarán de frecuentarla. Las mujeres dejarán de obedecerla. Es un buitre viejo».

Mignón: ¿Un buitre dijo? No pudo haber dicho «un buitre».

Hanna: (...) Dijo, además: «La tengo conmigo porque una mujer no se desgracia como un caballo». (Mignón se espanta). «La puse al lado mío para que me llevara las cuentas, y que ya no atendiera a la gente. Y hasta para eso es una inútil»»" (pp. 123-124).

La concatenación de rasgos negativos que expresa Hanna, quien introduce el discurso directo de Schlomo, refleja esta concepción utilitaria de la mujer y su cuerpo. Los términos 
despectivos y denigrantes que utiliza para remarcar las falencias físicas de Mignón, dan cuenta de ese proceso de cosificación: macilenta y fláccida; entrada en carnes, amarilla y enclenque. Además, el hecho que Schlomo no se deshiciera de ella y le buscara otra labor es otro indicio de su pensamiento utilitario. Según Schlomo, la mala condición física de Mignón, sumada a su avanzada edad, constituyen factores condicionantes que afectan la rentabilidad de un negocio que se sustenta fundamentalmente con la explotación del cuerpo femenino. Es por ello que Mignón termina siendo un «estorbo» para Schlomo, quien casi no obtiene réditos de ella debido a la baja demanda de los clientes.

Otra cuestión interesante a destacar de esta pieza es la forma en que se valoran los personajes femeninos a partir de sus atributos físicos. De esta manera, se hace del cuerpo "una realidad ajena que hay que evaluar, desarrollar y mantener a raya con el fin de obtener del mismo los resultados deseados, característica típica del individuo moldeado por la disciplina del trabajo capitalista" (Federici 2004: 211). En este sentido, la disputa que se establece entre Mignón y Hanna gira en torno al «precio» que tienen según sus cualidades:

"Hanna: Yo valgo treinta y cinco mil rublos, no lo olvide. Yo valgo lo que la
finca que regalaron a la zarina en Moscú para su último cumpleaños (...)

Mignón: Le juro que la voy a hacer matar.

Hanna: Usted, Ester, vale lo que el escarpín de la cocinera. Lana, esparadrapo y suciedad. ¿Cuánto es eso? ¿Veinte rublos? ¿Menos quizás? ¿Unos copecs apenas? ¿Cuánto es cinco copecs en pesos argentinos?” (pp. 127).

Al imponerse un determinado precio y valorarse a partir de él, Hanna se desliga completamente de su condición de sujeto y comienza a percibirse a sí misma como una mercancía. El hecho de compararse con la finca de la zarina no hace más que profundizar su condición de objeto. En contraposición, Hanna le impone a Mignón un precio insignificante en comparación al suyo, rebajándola a la condición de un objeto inservible y sin demasiado valor.

En «Desván» se plantea exactamente esta misma cuestión, en donde Tabita se compara con sus demás compañeras y se confiere un precio menor al de ellas debido a su mal estado de salud, el cual ha repercutido en su condición física. En este sentido, la enfermedad se convierte en un factor determinante que no sólo afecta la rentabilidad del negocio, sino que también provoca que la mujer tenga una concepción distorsionada de su cuerpo, al cual desvaloriza:

"Tabita: De todos modos, un rato conmigo vale nada más que tres pesos.

Paciencia. Yo no puedo cobrar cinco como vos o la Yvonne”. (pp. 159).

Al otorgar un precio a su propio cuerpo, Tabita lo transforma, de alguna manera, en una mercancía que se mira y se compara con el de sus compañeras. Como sostiene Cobo Bedia, la mujer no sólo está sujeta a la mirada del hombre, sino que también ellas "se miran mientras son miradas, una situación que determina tanto la relación entre los hombres y mujeres como la de las mujeres con ellas mismas, que existen como cuerpos objeto de la mirada" (2015: 14). En este sentido, los personajes femeninos de ambas piezas no sólo están sometidos a la mirada del hombre, quien les confiere cierto valor según sus características, sino que también se perciben a sí mismas y a las demás como una mercancía de consumo con un precio determinado. 


\section{Conclusión}

La prostitución se ha instituido, históricamente, como uno de los espacios de explotación y deshumanización más descarnados, el cual ha sometido a la mujer hasta reducirla a un mero objeto utilitario. Las piezas que integran Las polacas dan cuenta de este proceso de mercantilización del cuerpo femenino en su forma más cruda y brutal. Si bien la obra retrata una época determinada, en donde las mujeres eran concebidas más como objetos que como sujetos autónomos capaces de actuar y decidir por su cuenta, también reflejan las condiciones de sometimiento que aún perviven en la actualidad en sus distintas formas.

Cada una de las piezas de Las polacas constituye un eslabón en el proceso de mercantilización del cuerpo femenino. En «Historias tártaras» se plantea la primera etapa, el deseo de posesión, donde la mujer es proyectada e idealizada por el hombre desde una visión utilitaria como madre y esposa. En «Casamentera» se expone la segunda etapa, la de la transacción, donde las partes negociantes discuten el precio de la "mercancía" y los parámetros que determinan el valor de la misma. Finalmente, tanto «La Varsovia» como «Desván», constituyen la tercera y última etapa de este proceso, el reemplazo y posterior desecho del cuerpo. En ambas piezas, se puede observar la etapa final de esos cuerpos explotados y su posterior sustitución por una "mercancía" nueva, más joven y en mejores condiciones. Asimismo, estos personajes comienzan a asimilarse como mercancía, comparándose entre ellas según su valor de cambio, indicio de un total desligamiento de su condición de sujeto

Como ha sido siempre su función, el teatro crea escenas políticas donde, por inversión de la mostración, se apela a la resistencia tramada hoy en los distintos feminismos, los cuales "han visto el concepto de «cuerpo» como una clave para comprender las raíces del dominio masculino y de la construcción de la identidad social femenina" (Federici, 2010: 27). De esta forma, Patricia Suárez pone en escena una problemática que ejemplifica perfectamente este mecanismo de explotación sobre las mujeres, el cual las priva de su condición más esencial, su humanidad.

\section{Bibliografía}

ALEJANDRE PEÑA, M. T. (2000). El papel de la mujer en la sociedad capitalista y los derechos humanos. En T. Trujillo Flores (Ed.), Tercer Certamen de Ensayo sobre Derechos Humanos. Los Derechos Humanos de la Mujer (pp. 68-82). Toluca, México: Reyes \& Dávila Impresores.

COBO BEDIA, R. (2015). El cuerpo de las mujeres y la sobrecarga de sexualidad. Revista Investigaciones feministas, Vol. 6, 7-19. Recuperado de https://revistas.ucm.es/index.php/INFE/article/view/51376

COHEN DE CHERVONAGURA, E. (2011). La prostitución judía y su discurso a la luz de un expediente judicial. Revista Estudios Culturales de la Universitat Jaume I, Vol. IX, 31-51. Recuperado de http://aledar.fl.unc.edu.ar/files/Cohen-de-ChervonaguraElisa.pdf

FEDERECI S. (2010). Calibán y la bruja. Mujeres, cuerpo y acumulación primitiva. Madrid: Traficantes de Sueños. 
SCARSI, J. L. (2011). Historia de la prostitución y de la trata de personas en Buenos Aires. Recuperado de http://www.mercosursocialsolidario.org/valijapedagogica/archivos/hc/1-aportesteoricos/2.marcos-teoricos/2.documentos/2.Argentina-Historia-de-la-Prostitucion-yTrata-Jose-Luis-Scarsi.pdf

SCHNABEL, R. A. (2010). Historia de la trata de blancas en Argentina como persistencia de la esclavitud. Recuperado de http://elsolardelasartes.com.ar/pdf/683.pdf

SUÁREZ, P. (2006). Las polacas. Buenos Aires: Ediciones Teatro Vivo.

SUÁREZ, P. (2017). Las polacas. Rosario: Baltasara Editora. 